\title{
How relevant is hormone receptor status in the context of outcome to HER2-positive breast cancer?
}

\author{
Nadine Norton and Edith A Perez* \\ See related research by Vaz-Luis et al., http://breast-cancer-research.com/content/14/5/R129
}

\begin{abstract}
Clinical outcome of patients with breast cancer is based on patient and tumor-related factors. The relevant tumor-related factors include anatomical extent and biology. Of the prognostic and predictive biological markers available, hormone receptors (defined as estrogen and progesterone receptors) and HER2 receptors, have been independently validated. Pertinent questions to be addressed include their combined impact on prognosis, their relevance in terms of sites of metastases, and whether they change in primary versus recurrent tumors. Although these questions are being addressed in clinical trials, epidemiological results, such as those derived from the National Comprehensive Cancer Network dataset, add perspective to our understanding of these two most relevant biological prognostic/predictive markers.
\end{abstract}

\section{Introduction}

In this era of personalized medicine and emphasis on identifying prognostic and predictive molecular profiles, breast tumor testing for hormone receptor status and HER2 remain the most relevant markers for practice. In the manuscript accompanying this editorial, Vaz-Luis and colleagues [1] address the combined role of these markers on the natural history of disease and outcome after therapy.

Distinct differences in short- and long-term recurrence rates after a diagnosis of invasive estrogen receptor (ER)positive breast cancer have been previously documented $[2,3]$. Specifically, these tumors tend to recur at a pretty constant rate over many years. Clinical outcome of

*Correspondence: perez.edith@mayo.edu

Mayo Clinic, 4500 San Pablo Rd S., Jacksonville, FL 32224, USA patients with invasive HER2-positive breast cancer has been evaluated since 1998, when HER2 testing first received formal approval as predictive of benefit to the anti-HER2 therapy, trastuzumab. These tumors tend to have a peak of recurrence at 2-3 years from diagnosis, then a lower rate of recurrence, which have been uncovered with appropriate HER2 testing and interpretation [4-8]. The question at hand is how they interact with each other to predict clinical outcome. Cross-talk between ER and HER2 pathways may result in synergistic tumor progression, differential sensitivity to therapies, and differential sites of tumor relapse [9].

Well, what did the investigators find and how can we place it into the context of biology and other existing data? Vaz-Luis and colleagues are to be congratulated for gathering outcome data from 3,394 patients, diagnosed with HER2-positive breast cancer based on local laboratory testing between 2000 and 2007, and grouping them based on hormone receptor status. The exact type of HER2 testing or definition of positivity were not described, though presumed to be based on the US Food and Drug Administration (FDA)-approved guidelines [4], as the American Society of Clinical Oncology/College of American Pathologists guidelines first became available in 2007 [8]. Hormone receptor status was defined as ER and/or progesterone receptor $(\mathrm{PR})$ testing based on local analysis as described in their database; details of the type of testing or definition of positivity are not described. Appropriate stratifications for stage and receipt of adjuvant trastuzumab were performed; a cutoff age of 50 years was also used as a stratification factor, although its relevance may not be as strong as the other two. At a median follow up of 4 years (range 0 to 11 years), the investigators found that patients with hormone receptornegative disease experienced more cancer relapse in the short term, but found no differences in hazards of death beyond 5 years compared to those with hormone receptorpositive breast cancer. Another interesting aspect is the finding of increased risk of bone metastases for those 
with ER-positive disease, but no difference between the two subtypes (ER-positive or negative) in terms of risk of brain metastases. Finally, the study addressed consistency of hormone receptor and HER2 status in a subset of patients with primary and recurrent tumor testing, demonstrating an amazing $49 \%$ discordance of one of the three markers (ER, PR, HER2) from positive to negative or vice versa. These types of data strengthen the concept of obtaining tumor biopsies for biological testing at the time of diagnosis of metastatic disease, a step that may be crucial in optimizing decisions regarding systemic therapy. In our opinion, this biological testing should be considered as much a standard of care as anything else. There are two aspects (beyond central pathological tumor testing) that limit the scope of interpreting the data reported by Vaz-Luis and colleagues, in the context of biological relevance: first, only $17 \%$ of patients received adjuvant trastuzumab and data of use or duration of antiestrogen therapies used are not provided in the manuscript; and second, the retrospective nature of their analysis.

Our group's published data derived from prospectively conducted phase III trials in which central HER2 testing was performed along with hormone receptor status based on local laboratories (central hormone receptor testing is ongoing) are especially relevant $[6,7,10]$. With a median follow-up of 4 years in 4,045 patients in the combined analyses of two arms of N9831 and the B-31 trials, the 5 year recurrence rates for patients with hormone receptor-positive breast cancer receiving or not receiving adjuvant trastuzumab were $89.4 \%$ and $77.2 \%$, respectively, and $81.6 \%$ and $69.4 \%$ for those with hormone receptor-negative breast cancer who received or did not receive trastuzumab [6]. As per standards of care, the N9831 and B-31 trials pre-specified use of adjuvant hormonal therapy after completion of the chemotherapy portion of the treatment. These prospective studies identified clear differences in 5 year disease-free survival based on hormone receptor status. We recently presented longer (8+ year) follow-up data [10] demonstrating that the overall disease-free and overall survival differences based on hormonal receptor status appear to be only modestly different: for overall survival it was $84 \%$ in receptor negative compared to $88 \%$ in patients with hormone receptor-positive tumors. However, the recent 8-year data from HERA, presented at the 2012 San Antonio Breast Cancer Symposium, demonstrates similar recurrence rates by that time point. The convergence of these HER2+ data suggest differences in early rates of relapse based on hormone receptor status, with equilibration later on likely based on the use of anti-estrogen treatments [11]. One challenge with placing these data in the context of the study by Vaz-Luis and colleagues is that they aggregated the outcome of patients who received trastuzumab with those with HER2-positive disease who did not receive the antiHER2 therapy. This makes it difficult to ascertain the results for patients who were actually treated with trastuzumab. Discussions are ongoing related to whether we should have distinct trials for patients with HER2positive disease based on hormone receptor status, but we offer that this may help mainly with short-term datasets. An alternative approach is to acknowledge the impact of hormone receptor status, stratify based on such, and recommend anti-estrogens for patients with hormone receptor-positivity.

One interesting issue to be pursued is whether we should increase efforts to investigate bone-tropism and agents to decrease bone-metastases, for proactive use in patients with hormone receptor-positive disease. This will require devoting significant time and resources to identify other relevant molecular markers that will definitely impact future biological understanding and management decisions [12-14].

There is another piece of information in the manuscript by Vaz-Luis and colleagues that should not be overlooked, at least in terms of public health importance: $52 \%$ of patients were overweight or obese at study entry (body mass index $>25 \mathrm{~kg} / \mathrm{m}^{2}$ ). These data are consistent with our data in N9831 [15], in which we demonstrated that greater than $50 \%$ of patients had a body mass index $>25 \mathrm{~kg} / \mathrm{m}^{2}$. Although its impact was not evaluated in the manuscript by Vaz-Luis and colleagues, our N9831 study suggest that body mass index may also be another relevant biological factor that impacts clinical outcome for patients with HER2-positive disease. ER and PR testing is relevant in the context of HER2-positive disease: as predictive of benefit to anti-estrogens and differential 1 to 10 year term disease recurrence. Understanding its long-term relevance for overall survival beyond that time period requires longer follow-up data be available.

\section{Abbreviations}

ER, estrogen receptor; HER, human epidermal growth factor receptor; PR, progesterone receptor.

\section{Competing interests}

The authors declare that they have no competing interests.

Published: 14 January 2013

\section{References}

1. Vaz-Luis I, Ottesen RA, Hughes ME, Marcom PK, Moy B, Rugo HS, Theriault RL, Wilson J, Niland JC, Weeks JC, Lin NU: Impact of hormone receptor status on patterns of recurrence and clinical outcomes among patients with human epidermal growth factor-2-positive breast cancer in the National

Comprehensive Cancer Network: a prospective cohort study. Breast Cancer Res 2012, 14:R129.

2. Effects of chemotherapy and hormonal therapy for early breast cancer on recurrence and 15-year survival: an overview of the randomised trials. Lancet 2005, 365:1687-1717.

3. Early Breast Cancer Trialists' Collaborative Group (EBCTCG), Davies C, Godwin J, Gray R, Clarke M, Cutter D, Darby S, McGale P, Pan HC, Taylor C, Wang YC, 
Dowsett M, Ingle J, Peto R: Relevance of breast cancer hormone receptors and other factors to the efficacy of adjuvant tamoxifen: patient-level meta-analysis of randomised trials. Lancet 2011, 378:771-784.

4. Genentech Inc. Herceptin ${ }^{\circledR}$ (trastuzumab). US Prescribing information [online]. San Francisco, CA: Genentech Inc. 2008 [http://www.gene.com/ gene/products/information/pdf/herceptin-prescribing.pdf]

5. Perez EA, Suman VJ, Davidson NE, Martino S, Kaufman PA, Lingle WL, Flynn PJ, Ingle JN, Visscher D, Jenkins RB: HER2 testing by local, central, and reference laboratories in specimens from the North Central Cancer Treatment Group N9831 intergroup adjuvant trial. J Clin Oncol 2006, 24:3032-3038.

6. Perez EA, Romond EH, Suman VJ, Jeong J-H, Davidson NE, Geyer CE, Martino S, Mamounas EP, Kaufman PA, Wolmark N: Four-year follow-up of trastuzumab plus adjuvant chemotherapy for operable human epidermal growth factor receptor 2-postive breast cancer: joint analysis of data from NCCTG N9831 and NSABP B-31. J Clin Oncol 2011, 29:3366-3373.

7. Perez EA, Suman VJ, Davidson NE, Gralow JR, Kaufman PA, Visscher DW, Chen B, Ingle JN, Dakhil SR, Zujewski J, Moreno-Aspitia A, Pisansky TM, Jenkins RB: Sequential versus concurrent trastuzumab in adjuvant chemotherapy for breast cancer. J Clin Oncol 2011, 29:4491-4497.

8. Perez EA, Dueck AC, McCullough AE, Reinholz MM, Tenner KS, Davidson NE, Gralow J, Harris LN, Kutteh LA, Hillman DW, Jenkins RB, Chen B: Predictability of adjuvant trastuzumab benefit in N9831 patients using the ASCO/CAP HER2-positivity criteria. J Natl Cancer Inst 2012, 104:159-162.

9. Gluck S, Arteaga CL, Osborne CK: Optimizing chemotherapy-free survival for the ER/HER2-positive metastatic breast cancer patient. Clin Cancer Res 2011, 17:5559-5561

10. Romond EH, Suman VJ, Jeong J, Sledge GW, Geyer C, Martino S, Rastogi P, Gralow J, Swain SM, Winer EP et al: Trastuzumab plus adjuvant chemotherapy for HER2-positive breast cancer: Final planned joint analysis of overall survival (OS) from NSABP B-31 and NCCTG N9831. Cancer Res 2012, 72 (suppl 24):S5-5.

11. Goldhirsch A, Piccart-Gebhart MJ, Procter M, de Azambuja E, Weber HA, Untch M, Smith I, Gianni L, Jackisch C, Cameron D, Bell R, Dowsett M, Gelber
RD, Leyland-Jones B, Baselga J; the HERA Study Team: HERA TRIAL: 2 years versus 1 year of trastuzumab after adjuvant chemotherapy in women with HER2-positive early breast cancer at 8 years of median follow up. Cancer Res 2012, 72 (suppl 24):S5-2.

12. Sun Z, Asmann YW, Kalari KR, Bot B, Eckel-Passow JE, Baker TR, Carr JM, Khrebtukova I, Luo S, Zhang L, Schroth GP, Perez EA, Thompson EA: Integrated analysis of gene expression, $\mathrm{CpG}$ island methylation, and gene copy number in breast cancer cells by deep sequencing. PLoS One 2011, 6:e17490.

13. Asmann YW, Necela BM, Kalari KR, Hossain A, Baker TR, Carr JM, Davis C, Getz JE, Hostetter G, Li X, McLaughlin SA, Radisky DC, Schroth GP, Cunliffe HE, Perez EA, Thompson EA: Detection of redundant fusion transcripts as biomarkers or disease-specific therapeutic targets in breast cancer. Cancer Res 2012, 72:1921-1928.

14. Perez EA, Eckel-Passow JE, Ballman KV, Anderson S, Thompson EA, Asmann YW, Jen J, Dueck AC, Lingle WL, Sledge GW et al: Predictive genomic markers to chemotherapy and adjuvant trastuzumab via whole genome expression DASL profiling in the N9831 adjuvant study. Cancer Res 2012, 72 (suppl 24):PD10-04.

15. Crozier JA, Moreno-Aspitia A, Ballman KV, Martino S, Kutteh LA, Davidson NE, Kaufman PA, Perez EA: Correlation between BMI and clinical outcome of patients with early stage HER2+ breast cancer from the N9831 clinical trial. Cancer Res 2011, 71 (Suppl 3):P2-12-02.

doi:10.1186/bcr3335

Cite this article as: Norton N, Perez EA: How relevant is hormone receptor status in the context of outcome to HER2-positive breast cancer? Breast Cancer Research 2013, 15:101. 